\title{
ESTUDIOS LITERARIOS ECOCRÍTICOS, TRANSDISCIPLINARIDAD Y LITERATURA CHILENA
}

\author{
ECOCRITICAL LITERARY STUDIES, \\ TRANSDISCIPLINARITY AND CHILEAN LITERATURE
}

\author{
Arnaldo Donoso Aceituno \\ Universidad de Concepción. Concepción, Chile \\ arnaldodonoso@udec.cl
}

\begin{abstract}
Resumen: La ecocrítica deslinda un conjunto de prácticas investigativas caracterizadas por el diálogo experimental entre los estudios literarios, la ética ambiental, las ciencias, las humanidades y el pensamiento ecológico. Entendemos la ecocrítica como un territorio de conflicto y compenetración de saberes y prácticas heterogéneas, como un proceso de heterogénesis (Guattari). El artículo desarrolla una aproximación a los estudios literarios ecocríticos a partir de algunas investigaciones chilenas.
\end{abstract}

Palabras clave: Ecocrítica, literatura chilena, transdisciplinaridad, estudios culturales.

Abstract: Ecocriticism demarcates a set of investigative practices which are characterized by the experimental dialogue among literary studies, environmental ethics, science, humanities, and ecological thought. We understand ecocriticism as a territory of conflict and interpenetration of heterogeneous knowledge and practices, as a process of heterogenesis (Guattari). This article develops an approach to ecocritical literary studies based upon some Chilean research.

Keywords: Ecocriticism, Chilean literature, transdisciplinarity, cultural studies.

Recibido: 16.10.2014. Aceptado: 26.03.2015.

ACE dos DÉCADAS
AUE EL enfoque del análisis literario denominado eco-
crítica - estudios literarios ambientales, estudios literarios ecológicos,

${ }^{1}$ Ese es el consenso general: “Así, hacia 1993, los estudios literarios ecológicos 
crítica ecológica, crítica ambiental, indistintamente- viene contribuyendo a la reflexión transdisciplinar al promover el diálogo entre los estudios literarios, las ciencias, las humanidades, la ética y el pensamiento ecológico en un contexto de crisis medioambiental provocada por la acción del ser humano en los ecosistemas a escala global ${ }^{2}$. La ecocrítica, como un proyecto que reúne las cuestiones ambientales con los estudios literarios, tiene como objeto "movilizar la noción de medioambiente desde lo abstracto hacia un interés tangible" (Dixon, cit. Buell, 2005, p. 29) o, si se quiere, desde un espacio privado de visibilidad al espacio de lo público ${ }^{3}$. Su estrategia ha sido abrir el horizonte crítico y reflexivo hacia la investigación de diversos tópicos socio-ecológicos para difuminar las barreras entre el afuera y el adentro de los textos.

Esta condición intersticial es la puerta de entrada para debates sobre ecofeminismo, literatura étnica, arquitectura, cuestiones raciales, sustentabilidad, paisajismo urbano, justicia ambiental, ética extensionista, producción alimentaria, comparatismo, ecologías virtuales, etcétera. En efecto, no es fácil asimilar la pluralidad de puntos de vista al interior de los estudios ecocríticos. En una revisión de los últimos números de publicaciones como Interdisciplinary Studies in Literature and Environment, Journal of Ecocriticism (ISLE), Journal of Ecocriticism (JOE) o Ecozon@, nos encontraríamos, por ejemplo, con artículos que indagan en los modos de representación de los espacios naturales en la nature writing, investi-

emergieron como una escuela crítica reconocible" (Glotfelty y Fromm, 1996: xviii; cf. Clark, 2011, p. 5). "Este libro no podría haber sido escrito sino hasta el final del siglo $\mathrm{XX}$. El giro medioambiental en los estudios culturales y literarios emergió como un movimiento consciente de sí mismo hace casi una docena de años" (Buell, 2005, p. 1). En adelante, a menos que se indique, tanto las traducciones como los subrayados son nuestros.

${ }^{2}$ Según algunas proyecciones, los efectos de estos cambios podrían durar cientos o miles de años. En este contexto, podemos sostener que la actividad humana ha cambiado la Tierra a una escala sólo comparable con algunos colosales eventos de la naturaleza, al punto que en ciertos círculos científicos se ha cuestionado la vigencia de la denominación de nuestra actual era geológica, el Holoceno y planteado en su lugar la de Antropoceno (ver Crutzen y Stoermer, 2000; Zalasiewicz, Williams, Steffen y Crutzen, 2010).

${ }^{3}$ En sus "Notas sobre sistema y ecología" (2001), Lyotard puntualiza que la etimología de la palabra 'oikos' remite a la esfera de lo doméstico, de lo retraído, lo privado, lo que no se ve a simple vista. Es un hecho que los problemas ecológicos no son tan visibles como los problemas económicos. En consecuencia, la ecología es un discurso privado de visibilidad. 
gaciones sobre los desplazamientos del lenguaje de las ciencias naturales a la escritura creativa, la presencia del Mediterráneo en la poesía del sur de Italia, perspectivas poshumanistas sobre la cuestión de la animalidad, cartografías alimentarias en textos literarios del canon, la inscripción de los conflictos ambientales en ciertas literaturas regionales, reflexiones acerca de las tensiones entre lo local y lo global del pensamiento ecológico... Por este motivo, algunos especialistas plantean que más que una ecocrítica hay ecocríticas, diferentes aproximaciones estéticas, científicas, históricas, filosóficas, sociales, económicas, políticas, territoriales e ideológicas que piensan las interacciones entre naturaleza y cultura en textos literarios, siempre de un modo contingente y singular (Flys Junquera, Marrero y Barella, 2010) $)^{4}$.

En general, los ecocríticos manifiestan que no existen en el enfoque unos principios fundamentales ni una metodología uniforme (Oppermann, 2011). Más aún, algunos solicitan algo menos de fragmentación en el campo (Garrard, 2004; Clark, 2011). Ya en The ecocriticism reader: Landmarks in literary ecology (1996), texto seminal de la crítica ecológica, Cheryll Glotfelty entiende la ecocrítica como parte de un movimiento general de la disciplina de los estudios literarios hacia marcos cognitivos más fluidos, actitud característica del discurso teórico posmoderno. A este respecto, Serpil Oppermann constata que las diversas corrientes al interior de la crítica ecológica no comparten ni un objeto ni un lenguaje teórico común, pues el desarrollo del enfoque ha seguido una "trayectoria multidireccional" (2010, p. 17) vinculada al postestructuralismo, los estudios culturales, poscoloniales y a la agenda de la justicia ambiental ${ }^{5}$. De acuerdo a Oppermann, las nociones de heterogénesis y de rizoma de Félix Guattari y Gilles Deleuze, podrían explicar esta naturaleza multidireccional de la ecocrítica. El concepto de heterogénesis puntualiza un devenir de adaptación, transformación, modificación y vinculación constante de saberes y prácticas éticas con el entorno, mientras que la metáfora del rizoma distingue un estilo de pensamiento que actúa desde y hacia la conexión, la multiplicidad,

${ }^{4}$ Otros autores, como Lawrence Buell, evitan el término, privilegiando formas compuestas como crítica medioambiental o estudios literarios medioambientales. $\mathrm{Al}$ respecto, remitimos al prefacio del libro de Buell (2005).

${ }^{5}$ Ver, por ejemplo, el libro de G. Huggan y H. Tiffin (2010). 
la diferencia, la asistematicidad, la transversalidad, la ruptura asignificante y la colectividad en contraste con los modelos epistémicos positivistas (Oppermann, 2010, p. 19; cf. Guattari, 1990; Deleuze y Guattari, 2006). La articulación de ambos conceptos -y otros como el de "agenciamiento colectivo de enunciación" - permite a Oppermann afirmar que la ecocrítica desafía el estilo de pensamiento arborescente que, por definición, privilegia las estructuras jerárquicas y excluye las diferencias (18).

En la presentación del número 38 de Acta Literaria, Juan Zapata sostiene que la "investigación y la crítica literarias no son ajenas al proceso desestabilizador que experimenta el conocimiento, condicionado por nuevas realidades económicas, tecnológicas y culturales" (2009, p. 5). Los textos, discursos y prácticas literarias mutan de acuerdo a las nuevas condiciones -sociedad del conocimiento, contexto de incertidumbre, hiperrealidad, simulacro, creciente tecnologización, debilitamiento de las fronteras territoriales, economías globales, libre circulación de bienes y servicios, nueva percepción del espacio-tiempo- y, consecuentemente, investigadores y críticos deben desarrollar nuevas estrategias de análisis para aproximarse a sus objetos de estudio. En términos específicos, concluye Zapata, "la investigación y la crítica literarias han devenido transdisciplinarias y experimentales" (7). Prueba de ello es que el XVIII Congreso de la Sociedad Chilena de Estudios Literarios (SOCHEL) tuvo como foco los "Procesos de transdisciplinariedad e interculturalidad en la construcción de identidades culturales y literarias"6, además de ser el primer evento de esta sociedad científica que organiza una mesa exclusiva para estudios ecocríticos. Ambos hechos corroboran la insistencia de la investigación y crítica literaria chilena por reflexionar sobre la formalización académica de la transdisciplinaridad 7 , al tiempo que legitiman a los estudios literarios ambientales como un lugar de conflicto y compenetración de saberes y prácticas situadas que aprehenden simultáneamente lo racional y lo relacional (Richard, 2001; cf. Aronson, 2003; Max-Neef, 2005).

${ }^{6}$ Osorno, Universidad de Los Lagos, 07 al 10 de noviembre de 2012.

${ }^{7}$ Investigadores como Oppermann opinan que la ecocrítica "se ha transformado en un campo verdaderamente transdisciplinar" (2011, p. 16). Las preocupaciones ecocríticas, anota Úrsula Heisse, "han posibilitado, sobre todo los últimos años, una colaboración transdisciplinaria” (2013, p. 641). 
En esta dirección, la ecocrítica puede asociarse a las modalidades discursivas de la crítica cultural, es decir, a aquellos "textos intermedios que no quieren dejarse localizar según los parámetros institucionales que definen los saberes ortodoxos" (Richard, 2001, p. 144). Con todo, ciertos círculos académicos han visto con desconfianza la instalación de la crítica ecológica, como si se tratase de un trasplante mecánico y acrítico de teorías post, "otra moda más en las aulas", como ironiza Niall Binns, cuando no una perspectiva "colonizante y subvaloradora de las tendencias que tienen su origen y singularidad en la región" (Prado, 2010, p. 19; cf. Marrero, 2011, pp. 27-29) ${ }^{8}$. Legítima sospecha que mueve a Marcela Prado a proponer una línea de estudios que denomina etnocrítica, cuya principal preocupación es el "conocimiento del espacio/paisaje americano y nacional como elemento de identidad profunda de la región latinoamericana” (Prado, 2010, p. 122). En "Poesía, espacio/paisaje e identidades en las literaturas latinoamericanas" (2010), Prado concibe la etnocrítica como una "particular manifestación [...] de lo que en Estados Unidos han llamado ecocrítica” (120). La etnocrítica se propone estudiar la "identidad y diversidad cultural, particularmente centrada en la percepción de la naturaleza” y "la naturaleza como otredad integrada con otros grupos marginados (indígenas, etnias, grupos coloniales, flora y fauna)" (ibíd.). La propuesta decolonizadora de Prado traduce con fidelidad las lecciones de un Cornejo Polar o un Raúl Bueno de leer desde nuestros contextos de realidad $^{9}$, pero, a la vez, recoge la visión

\footnotetext{
${ }^{8}$ Resulta conveniente aclarar que esta desconfianza por lo eco es muy anterior a la ecocrítica. Ya en los 70’ el intelectual chileno Luis Oyarzún manifestaba en Defensa de la Tierra: "algunos han solido ver en la ecología y la defensa de la tierra una nueva máscara del imperialismo para desviar la atención de las masas, sobre todo juveniles" (1973, p. 56). Oyarzún fallece el 25 de noviembre de 1972. Semanas antes Universitaria publica el volumen Ecología y revolución (una recopilación de las intervenciones de S. Mansholt, E. Maire, M. Bosquet, E. Goldsmith, E. Morin, P. Saint Marc y H. Marcuse, en un debate que el periódico francés Le Nouvel Observateur organizó el 13 de junio de 1972, en paralelo a la primera Conferencia de Naciones Unidas sobre el Medio Humano o Cumbre de la Tierra, desarrollada en Estocolmo entre el 5 y el 16 de junio de 1972), libro que vino a congregar los espíritus radicales con el ecologismo.

9 "Al decir de la investigadora brasileña Marisa Lajolo, tenemos en América Latina una tradición 'grande' de estudios literarios que encajan en lo que se denomina estudios culturales, aunque el nombre no haya saltado acá a la palestra [...] Dicho de otra manera, no habremos inventado el término, pero hemos diseñado y cultivado el campo, desde antiguo y extensamente, de acuerdo a nuestras necesidades" (Bueno, 2001, p. 74).
} 
del paradigma de la complejidad de Edgar Morin, el pensamiento de Régis Debray, los estudios ecocríticos (Glotfelty y Fromm, Armbruster y Wallace, Buell, Bate, Love, y otros) y los estudios culturales, en especial el binomio Sarlo/Williams. Así, lo que finalmente queda a la vista en el ensayo, dejando de lado sus reservas programáticas, es la viralización de los estudios literarios ambientales y su potencial para establecer cruces teóricos productivos.

La propuesta anterior no difiere de otras investigaciones chilenas que limitan, en determinados aspectos, con los estudios literarios ecocríticos y que revelan una tendencia transversal a pensar en verde, independientemente de la especialización en el campo (cf. Binns, 2010) ${ }^{10}$. En efecto, es significativo que un correcto crítico como Jaime Concha advierta en Neruda una defensa "de la alteridad no-humana" y "sugerencias sobre la liberación animal” (2010, p. 144; 2013, p. 250). Relacionando las ideas del filósofo Peter Singer con el obsesivo imaginario animal que Neruda despliega desde Estravagario (1958), Concha colige que el núcleo de esta sensibilidad parece encontrarse en el "animal explotado que Neruda vio

${ }^{10}$ En relación con la presencia de autores chilenos -principalmente poetas, en desmedro de narradores, dramaturgos y ensayistas, a excepción del trabajo de Andrea Casals que comento líneas más adelante- en estudios ecocríticos a nivel hispanoamericano, son interesantes las aportaciones del profesor peruano Roberto Forns-Broggi, radicado en Denver, en especial su libro Nudos como estrellas. ABC de la imaginación ecológica en nuestras Américas (2012), especie de glosario ecocrítico que repasa algunos clásicos chilenos (G. Mistral, P. Neruda, N. Parra, G. Rojas) y otros más contemporáneos (T. Harris, C. Basso, J. P. Riveros). De otras latitudes, pero no por eso menos cercanos a nuestras realidades, tenemos a Steven White y Niall Binns, con sendos estudios sobre literatura chilena. El profesor y poeta británico N. Binns tiene una amplia experiencia en literatura chilena, en específico en la poesía de Nicanor Parra y Jorge Teillier. Ha escrito numerosos artículos y ensayos sobre ecocrítica. Publicó en 2004 ¿Callejón sin salida? La crisis ecológica en la poesía hispanoamericana, libro que sistematiza sus preocupaciones sobre las múltiples aristas de la crisis ecológica en poetas del canon como Neruda, Mistral y Parra. Por su parte, el estadounidense Steven F. White ha publicado varios trabajos sobre poesía chilena, entre los que destacan "Los ríos en la poesía chilena: nuevas definiciones ecocéntricas de la poesía épica y lírica" (2009) y su reciente antología El consumo de lo que somos. Muestra de poesía ecológica hispánica contemporánea (2014). En esta última, White presenta una selección de poemas del chileno-huilliche Jaime Luis Huenún. En el curso de la revisión final de este artículo apareció el número 79 de la Revista de Crítica Literaria Latinoamericana $(R C L L)$ que contiene el dossier "Ecocrítica en América Latina", a cargo de la argentina Gisela Heffes. Entre los autores chilenos que son objeto de análisis se cuentan Antonio Gil, Leonel Lienlaf y Roberto Bolaño. Lamentablemente, a la fecha no hemos tenido acceso al volumen. 
en el Oriente, escarnecido en los zoológicos y en el circo de la civilización occidental-cristiana, hecha a la medida de nuestra soberbia antropocéntrica" (Concha, 2010, pp. 144-145) ${ }^{11}$.

Del mismo modo, la crítica ha visualizado en la poesía chilena escenarios distópicos y/o apocalípticos en los que se representa a los referentes naturales como meros "residuos simbólicos”. Así, el análisis de Óscar Galindo (2004) de las narrativas de contaminación y degradación de lo real en la poesía de Oscar Hahn y Gonzalo Millán. Del otro lado, Sergio Mansilla ha estudiado las tensiones entre los imaginarios tradicionales de la isla de Chiloé y la entrada de una modernidad materializada en el modo de producción capitalista de las empresas acuícolas en su artículo de "Mutaciones culturales de Chiloé: los mitos y las leyendas en la modernidad neoliberal isleña" (2009). La huella de una realidad que se desvanece, pero que sigue viva en la literatura, también es seguida por Alida Mayne-Nicholls en su ensayo acerca de las comidas y bebidas en la poesía de Jorge Teillier (2012), en el que se propone que las materias tienen una voz que infiltra la memoria autobiográfica del poeta.

Indagando en los procesos de incorporación de la poesía mapuche al canon literario chileno, y los espacios en y de la poesía indígena, Claudia Rodríguez Monarca ofrece una sugerente mirada sobre materias que permean no sólo las prácticas discursivas de parlamento intercultural, sino también las rituales, "la mediación entre el mundo natural y el mundo sobrenatural”, la comunicación entre "lo mundano con lo sagrado" (Rodríguez, 2005, 2013). Lo mismo Juan Manuel Fierro y Orietta Geeregat, quienes en "La memoria de la Madre Tierra: el canto ecológico de los poetas mapuches" (2004) abordan la problemática de la memoria, el vínculo con el entorno y la preocupación ecológica en textos de la poesía mapuche contemporá-

${ }^{11}$ A diferencia de Concha, pienso que el "obsesivo imaginario" y "las sugerencias de liberación" son anteriores a Estravagario. En Canto General (1950) encontramos, por ejemplo, los poemas "Los enigmas" ("Sin duda me preguntaréis por el marfil maldito del narwhal, / para que yo conteste / de qué modo el unicornio marino agoniza arponeado") y el aún más elocuente "Las aves maltratadas" ("Llegaron [los hombres...] / con garrotes / y con cestos, robaron el tesoro, / apalearon a las aves, derrotaron / nido a nido la nave de las plumas, / sopesaron los huevos y aplastaron / aquellas que tenían criatura”). Hemos trabajado esta hipótesis con Juan Gabriel Araya en el artículo "Representaciones animales en la poesía de Pablo Neruda", a publicarse en Literatura: teoría, historia y crítica, vol. 18, núm. 1 (2016). 
nea (Queupul, Chihuailaf, Huenún, Millahueique, Quintupil Añiñir, entre otros). En su artículo, Fierro y Geeregat dan cuenta del valor colectivo de una palabra que elabora y sueña la utopía ancestral del trato recíproco entre lo humano y lo extrahumano desde el registro de la denuncia y el ejercicio de la memoria.

Esta especie de espiritualidad material, observada en la poesía mapuche por C. Rodríguez, Fierro y Geeregat, también puede visualizarse en la poesía de Mistral. En "Tierra y territorio: La huella de una alianza en la escritura mistraliana" (2001), Edson Faúndez plantea que la elquina no se mueve por sino con la tierra. Escritura y entorno (la pampa, el Valle de Elqui, la Cordillera de los Andes) se encuentran en un mismo plano y componen un bloque de puro movimiento del que emergen devenires y fugas políticas, como el americanismo y el indigenismo mistraliano. También en el terreno de la escritura femenina, Sebastián Schoennenbeck (2012) ha estudiado los jardines y paisajes presentes en la obra de María Luisa Bombal. Para Schoennenbeck, la naturaleza es ineludible al describir la narrativa de Bombal (64). El crítico descubre una relación especular de lo femenino con lo telúrico, relación que comporta valores de identificación, extravío y desdibujamiento del yo. Por último, destacamos una nota sobre el Diario íntimo (1995) de Luis Oyarzún, en la que Fernando Pérez Villalón reflexiona sobre el "ecologismo humanista-cristiano" del escritor chileno (1999, pp. 105-107). En pocas palabras, el ecologismo de Oyarzún trascendería el antropocentrismo que se encuentra en la base de la cristiandad.

Se observa, igualmente, el desplazamiento inverso, esto es la asimilación de modelos hermenéuticos literarios por otras disciplinas. Por ejemplo, el experto en bioética Raúl Villarroel ${ }^{12}$ (1997) ha analizado un corpus de la poesía nerudiana desde los conceptos heideggerianos de "vecindad" y "copertenencia". Villarroel estima que la poesía de Neruda "no es concebible en términos simplemente antropocéntricos o geocéntricos", porque en ella sólo es posible reconocer la pertenencia de lo humano a lo extrahumano.

12 Villarroel es autor de La naturaleza como texto: hermenéutica y crisis medioambiental (2006), un riguroso estudio que examina el desarrollo de las comprensiones ético-filosóficas de la naturaleza, desde la antigua Grecia hasta la actualidad, al tiempo que formula algunas "condiciones de posibilidad" de una nueva ética que se enfrente al imperativo tecnocientífico. 
La escritura nerudiana concierne a una realidad que no cede su esencia "al hombre y su dispositivo lógico de comprensión, para el que resulta inabordable o imposible de dominar" (Villarroel, 1997). Interesante también es el trabajo del biólogo Ricardo Rozzi (Aillapán y Rozzi, 2004), quien ha escrito sobre la poesía de Lorenzo Aillapán, desde la ética ambiental y las ciencias ecológicas. Aillapán, el "hombre-pájaro", poeta lafkenche, dice comunicarse con las aves y hablar por ellas. Rozzi analiza las representaciones ornitológicas mapuche presentes en los poemas-cantos de Aillapán para luego presentar sus semejanzas y diferencias con las descripciones científicas a través de una metodología que integra la ornitología, la ecología de comunidades, la antropología y la ética.

Investigaciones como las reseñadas comparten no sólo el carácter fluido que define la investigación ecocrítica. Además, en general, abordan cuestiones axiológicas referentes a nuestra relación con lo no humano. Saliendo del terreno de las aproximaciones, recalamos en proyectos propiamente ecocríticos. En nuestro medio, las investigaciones de Juan Gabriel Araya y Mauricio Ostria son pioneras ${ }^{13}$. La relectura de obras canónicas, el desarrollo y la reelaboración de conceptos y categorías, las visiones de proceso de la representación del entorno y las materias, la relectura y resemantización de textos olvidados, el estudio de literaturas locales y la autorreflexividad de la práctica ecocrítica, constituyen el grueso de sus preocupaciones. Los contextos de aplicación de sus estudios han sido la poesía y la narrativa chilena del siglo XX. Una breve revisión de sus alcances nos permitirá cartografiar la condición de los estudios literarios medioambientales en Chile.

Araya se ha referido en "Un territorio más allá: convergencias ecológicas en la cuentística de Francisco Coloane" (2009) a la compleja red de asociaciones biológicas y ecológicas en los relatos del autor. En opinión de Araya, Coloane supera el verosímil del neorrealismo de la generación del '38, pues plantea una experiencia límite de la escritura al integrar "conte-

${ }^{13}$ Las investigaciones ecocríticas de Araya (Universidad del Bío-Bío) y Ostria (Universidad de Concepción) se inscriben en un esfuerzo sistemático que se inició en 2006 con el proyecto de Desarrollo de la Docencia "Literatura y ecología" en la Universidad del Bío-Bío, ampliado en 2007 con el proyecto regular "Literatura chilena y ecología", en la misma institución. Luego, en conjunto, Araya y Ostria desarrollaron el proyecto FONDECYT "Lecturas ecocríticas de la literatura chilena del siglo XX", entre 2008 y 2011. 
nidos provenientes de disciplinas científicas como la botánica, paleontología, geografía, historia, oceanografía, etnografía, geología y la ecología” (41) para reconstruir un relato totalizador que rehúye la mera mímesis. En la mayor parte de los cuentos de Coloane hay un correlato ético e ideológico referido a la depredación del entorno. Una visión de conjunto de la cuentística de Coloane nos revela que es un mapa de los flujos de vida y de las interacciones interespecies del extremo sur chileno: la escritura de Coloane revela cruces de cuerpos humanos y no humanos cooperando para la subsistencia en un territorio hostil. Los términos "convergencia" y "simbiosis cooperativa" caracterizan la relación entre perros, caballos y hombres en las soledades australes (Araya, 2009, pp. 43-44).

Otro de los estudios de Araya (2011) indaga en los modos de representación estética de la naturaleza maulina y el concepto darwinista de selección natural en Zurzulita (1920) de Mariano Latorre, obra fundamental del criollismo. En pocas palabras, Latorre es "un hombre para quien la naturaleza existe" (Vaïsse cit. Araya, 2011, p. 51). Prueba de ello es la crítica del narrador maulino a sus contemporáneos: estos no revelaron en su integridad la tierra como fundamento de la vida y del hombre. El problema, de acuerdo con Latorre, se arrastra desde el texto fundacional de la nación chilena: La Araucana. Para el maulino, Ercilla viajó admirando "un paisaje convencional", limitado por su educación clásica. Así, "al mirar el encaje de un coigüe, o en la simetría de un alerce, no vio sino árboles, como todos los árboles que conocía”, a diferencia del jesuita Alonso de Ovalle quien "poseyó más que nadie, el don poético y el profundo sentido de la belleza natural de su tierra nativa" (46). La red de preferencias y exclusiones de la escritura de Latorre acoge una acusada reflexividad. La fuerza expresiva de la novelística latorreana nace del análisis del paso del ser humano por los espacios naturales. Para Araya, el determinismo telúrico implica no solo la visión evolutiva, sino también un conocimiento profundo, material y experiencial del orden y economía de la naturaleza. El ideal de Mateo Elorduy, protagonista de Zurzulita, de cambiar su abúlica vida a través de la vida en el campo se ve abortado por aquello que no conoce: una naturaleza omino$s a$, alterada por la presencia de lo extraño.

El análisis de Araya de la narrativa de Luis Sepúlveda y Darío Oses (Araya, 2010, 2011, 2012) es legible en el contexto de las sociedades contemporáneas. La obra del primero es revisitada desde el "principio de res- 
ponsabilidad” del filósofo alemán Hans Jonas. Para Araya, Luis Sepúlveda desarrolla una econarrativa basada en un discurso crítico de una ética que excluye de su campo de interés los cambios en los modos de vida humanos, que pierde de vista la dignidad intrínseca del humano como parte de un sistema integrado, que no desarrolla o legitima un saber predictivo acerca de las consecuencias en la biósfera de los avances tecnocientíficos en el contexto de globalización ni asume la idea de futuro del Sistema-Tierra (Araya, 2012, p. 152). En otro nivel de análisis, Sepúlveda sería un representante del género ecopolicial, es decir, el relato de la investigación y resolución de un crimen ecológico, como puede apreciarse en las novelas Mundo del fin del mundo (1994) o Yacaré (1998). En una orientación similar, la novela 2010: Chile en llamas de Darío Oses es un fiel representante de la narrativa distópica. Normativación, control biopolítico a través del libre mercado, tecnocultura, drogas legales y contaminación ambiental, son los elementos temáticos del relato. La novela conecta con varios postulados posmodernistas -sociedad del espectáculo, nihilismo, estética del simulacro, sociedad de alta tecnología- al proyectar la intensificación de los procesos económicos y tecnocientíficos del capitalismo tardío y su impacto en los modos de vida humanos. Siguiendo una tradición de utopías negativas totalitarias como Brave New World (1932) o 1984 (1949), Oses da vida a un mundo cuyos principios rectores son dictados por un neoliberalismo fuera de control. 2010: Chile en llamas es una "ficcional versión chilena del fin de la historia" (Araya, 2010, p. 34), pues aniquila los últimos puntos de referencia de la modernidad, proponiendo en su lugar "el eclipse radical de la propia naturaleza humana” (Jameson, cit. Araya, 2010, p. 33).

Por su parte, Mauricio Ostria ha examinado la "conciencia ecológica activa” de los sujetos textuales de la gran poesía chilena del siglo XX. La imitación del devenir generativo de la naturaleza en la teoría creacionista de Vicente Huidobro equivale a la puesta en diálogo de materias heterogéneas -animales, plantas, mitos, lenguas, máquinas, geografías, objetos-en una compleja red en la que coexisten lo humano y lo no humano. En opinión de Ostria, la crítica suele calificar la poesía de Huidobro a partir de las afirmaciones provocativas de su primera etapa creacionista, momento en el que reniega de la naturaleza y la mímesis. No obstante, sus poemas desdicen las más de las veces la hipertrofia metapoética y antropocéntrica del discurso creacionista ortodoxo. Las imágenes y malabarismos creacionis- 
tas yuxtaponen referentes naturales y artificiales que se cruzan, agencian, en un vínculo complejo y paradójico, en un "esfuerzo por considerar en conjunto el devenir humano y el biológico a escala planetaria” (Morin, cit. Ostria, 2008, p. 228). De este modo, donde fracasa la teoría del "pequeño dios" ganan los agenciamientos, conformaciones mutantes que progresivamente van siendo reemplazadas por referentes del mundo natural (Ostria, 2008, pp. 232, 255). En el último Huidobro, el de Ver y palpar (1941) y Últimos poemas (1948), entre otros títulos, la subjetividad allana un camino de alianza con lo no humano, perfilando una conciencia de integración del poeta en la naturaleza, un devenir imperceptible: "un advenimiento del silencio preñado de sentido, que es al fin, el misterio de la poesía” (231).

Esta comprensión de "la subjetividad como un complejo bio-socio-cultural" (Ostria, 2010b), pero con un alto coeficiente de territorialización, es también observada de modo sistemático tanto por Araya como por Ostria en la poesía de Rosabetty Muñoz, Sonia Caicheo, Juan Pablo Riveros, Sergio Mansilla, escritores que hacen legibles los territorios australes (la selva valdiviana, la Patagonia, del archipiélago de Chiloé y los confines antárticos) en el marco de la defensa de los valores culturales regionales frente a los procesos de globalización (Ostria, 2010b, p. 97). Finalmente, ambos investigadores han ahondado en las dos principales visiones canónicas sobre la crisis del sujeto moderno y la aparición del pensamiento ecologista: las connotaciones ecologistas del ciclo de las odas de Neruda, en especial "Oda a la erosión en la provincia de Malleco", de Nuevas odas elementales (1956), y en los Ecopoemas (1982) de Nicanor Parra (Araya, 2008; Ostria, 2010b).

Mención aparte merece la tesis de doctorado Fundamentos para la lectura ecocrítica en Chile (2015) de Andrea Casals, académica de la Pontificia Universidad Católica de Chile. En 2011, Casals había publicado el artículo "Puerto Edén: ¿puerto o paraíso? Una lectura ecocrítica de Ayayema, de María Asunción Requena”, breve trabajo que explora la forma en que la dramaturga representa el entorno natural para documentar el encuentro del kaweskar con el hombre blanco. Respecto de la tesis de Casals, puede señalarse que tiene una robusta base teórica-metodológica. A partir de la lectura de Gabriela Mistral, Nicanor Parra y Adriana Paredes Pinda, Andrea Casals releva categorías analíticas específicas para el examen de la ecopoesía, es decir, aquellas prácticas poéticas en sintonía con la naturaleza. 
Parece ser que la única coherencia posible para los estudios ecocríticos es explorar todas las facetas de la experiencia literaria y creativa desde un punto de vista medioambiental, pero sin restringirse sólo al relato de las problemáticas (cf. Adamson y Slovic, 2009). Baudrillard manifiesta suspicazmente que "la cantinela ecológica oculta que no es la energía material lo que desaparece del horizonte de la especie, sino la energía de lo real, la realidad de lo real" (1994, pp. 66-67). Haciendo eco de esta idea, estimamos que el ímpetu indagativo se abrirá en Chile, en el corto plazo, a un corpus no canónico y a preocupaciones culturales heterogéneas. Lo queer en función de las políticas del cuerpo y su vínculo con el entorno, la relación entre lo humano y la tecnología, la ecología lingüística, el sentido del lugar en la poesía lárica y étnica, los territorios existenciales de la literatura chilena post 2000, el discurso tóxico y la basura -material y metafórica- en la crónica urbana, la cuestión de la animalidad, perspectivas poscoloniales y decoloniales de justicia medioambiental, los modos de representación de los espacios y agentes en la dramaturgia contemporánea, la llamada ecología gris (Virilio) y de los regímenes de signos (Volli), la narrativa de ciencia ficción, serán sin duda algunos de los temas de interés ecocrítico. Asimismo, la ecocrítica deberá trascender la literatura y considerar prácticas artísticas interdisciplinares -la escritura en el cielo y en el desierto de Raúl Zurita son un buen ejemplo. La sola posibilidad de pensar estos y otros objetos de análisis franquea el programa primitivo de "la aplicación de la ecología y conceptos ecológicos al estudio de la literatura” (Ruecker, 1978, cit. Glotfelty y Fromm 1996: xx), o el de estudiar "las conexiones entre literatura y medioambiente" (xviii), expandiendo el enfoque ecocrítico y asegurando su continuidad en un contexto de agotamiento de la literatura, de la teoría y de la creatividad. En conclusión, su propósito no es establecerse como un cuerpo disciplinar fijo e impermeable, sino mantenerse como un enfoque crítico y creativo, en movimiento incesante.

\section{Referencias}

Adamson, J. y Slovic, S. (2009). The Shoulders We Stand On: An Introduction to Ethnicity and Ecocriticism. MELUS, 34(2), 5-24.

Aillapán, L. y Rozzi, R. (2004). Una etno-ornitología mapuche contemporánea: 
poemas alados de los bosques nativos de Chile. Ornitología Neotropical, $15,419-434$.

Araya, J. G. (2006). Ética, política y poética: hacia una lectura ecocrítica de Pablo Neruda. Revista de Crítica Literaria Latinoamericana, 63-64, 253-263. . (2008). Nicanor Parra. De la antipoiesis a la ecopoiesis. Estudios Filológicos, 43, 9-18.

. (2009). Un territorio más allá: convergencias ecológicas en la cuentística de Francisco Coloane. Literatura y Lingüística, 20, 41-55. . (2010). Distopía y devastación ecológica en 2010: Chile en llamas (1998) de Darío Oses. Acta Literaria, 40, 29-44.

. (2011). Novela de la Tierra: Consideraciones ecocríticas sobre Zurzulita (1920) de Mariano Latorre. Anales de Literatura Chilena, 12, 49-60.

. (2012). Otra ética para un nuevo mundo: El "principio de responsabilidad” de Hans Jonas en Mundo del fin del mundo (1994) de Luis Sepúlveda. Notas para una investigación ecocrítica. Acta Literaria, 44, 153-165. Aronson, P. (2003). La emergencia de la ciencia transdisciplinar. Cinta de Moebio, 18, 179-90.

Baudrillard, J. (1994). Olvidar a Foucault. Valencia: Pre-Textos.

Binns, N. (2001). Ecocriticism: Otra moda más en las aulas. Babab, 7. En http://www.babab.com/noo7/ecocritica.htm.

. (2004). ¿Callejón sin salida? La crisis ecológica en la poesía hispanoamericana. Zaragoza: Prensas Universitarias de Zaragoza.

. (2010). Ecocrítica en España e Hispanoamérica. Ecozona, 1, 132-135.

Buell, L. (2005). The future of environmental criticism: Environmental crisis and literary imagination. Oxford: Blackwell.

Bueno, R. (2001). Notas sobre los estudios culturales en y sobre América Latina: El reclamo de Antonio Cornejo Polar. Signos Literarios y Lingüísticos, III(1), 69-85.

Casals, A. (2015). Fundamentos para la lectura ecocrítica en Chile (Tesis doctoral no publicada). Pontificia Universidad Católica de Chile.

Clark, T. (2011). The Cambridge Introduction to Literature and the Environment. Cambridge: Cambridge University Press.

Concha, J. (2010). Neruda: poeta del siglo XX. Revista Chilena de Literatura, $65,143-152$.

. (2013). Confieso que he vivido y su dimensión transpoética. Anales de Literatura Chilena, 19, 227-253.

Crutzen, P. y Stoermer, E. (2000). The Anthropocene. The International Geosphere-Biosphere Programme (IGBP) Newsletter, 41, 17-18. Recuperado de http://www.igbp.net/download/18.316f18321323470177580001401/NL41. pdf

Deleuze, G. y Guattari, F. (2006). Mil mesetas: capitalismo y esquizofrenia. Valencia: Pre-Textos. 
Faúndez, E. (2001). Tierra y territorio: La huella de una alianza en la escritura mistraliana. Signos, 34, 3-20.

Fierro, J. M. y Geeregat, O. (2004). La memoria de la Madre Tierra: el canto ecológico de los poetas mapuches, Anales de Literatura Hispanoamericana, 33, 77-84.

Flys Junquera, C., Marrero, J. M. y Barella, J. (eds.). (2010). Ecocríticas: Literatura y medioambiente. Madrid/Frankfurt: Iberoamericana/Vervuet.

Forns-Broggi, R. (2012). Nudos como estrellas. ABC de la imaginación ecológica en nuestras Américas. Lima: Nido de Cuervos.

Galindo, O. (2004). Distopía y apocalipsis en la poesía de Óscar Hahn y Gonzalo Millán, Anales de Literatura Hispanoamericana, 33, 65-76.

Garrard, G. (2004). Ecocriticism. Londres: Routledge.

Gifford, T. (2010). Un repaso al presente de la ecocrítica. En C. Flys Junquera, J. M. Marrero y J. Barella (eds.), Ecocríticas. Literatura y medioambiente (pp. 67-87). Madrid/Frankfurt: Iberoamericana/Vervuet.

Glotfelty, C. y Fromm, H. (eds.). (1996). The ecocriticism reader: Landmarks in literary ecology. Athens, Georgia: University of Georgia Press.

Guattari, F. (1990). Las tres ecologías. Valencia: Pre-Textos.

Heisse, U. (2013). Globality, Difference, and the International Turn in Ecocriticism. PMLA, 128(3), 636-643.

Huggan, G. y Tiffin, H. (2010). Postcolonial ecocriticism: Literature, animals, environment. Nueva York: Routledge.

Lyotard, J. F. (2001). Notas sobre sistema y ecología. En G. Vattimo (comp.), La secularización de la filosofía: Hermenéutica y posmodernidad (pp. 275-282). Barcelona: Gedisa.

Mansilla, S. (2009). Mutaciones culturales de Chiloé: los mitos y las leyendas en la modernidad neoliberal isleña. Convergencia. Revista de Ciencias Sociales, 51, 271-299.

Marrero, J. M. (ed.). (2011). Literatura y sostenibilidad en la era del antropoceno. Las Palmas de Gran Canaria: Fundación Canaria Mapfre Guanarteme.

Max-Neef, M. (2005). Foundations of transdisciplinarity. Ecological Economics, 53, 5-16.

Mayne-Nicholls, A. (2012). Jorge Teillier: La inscripción de una historia familiar. Acta Literaria, 45, 65-80.

Morin, E. (1996). El pensamiento ecologizado. Gazeta de Antropología, 12. En http://www.ugr.es/ pwlac/G12_o1Edgar_Morin.html

Nordenflycht, A. (2009). Tensiones entre literatura, ciencia, experiencia e historia en un intelectual de la sattelzeit hispanoamericana. Alpha, 29, 23-40. . (2010). Paratopía del exilio jesuita americano: Historia natural y narración literaria en Juan Ignacio Molina, Francisco Javier Clavijero y Juan de Velasco. Acta Literaria, 40, 91-108. 
Oppermann, S. (2010). The Rhizomatic Trajectory of Ecocriticism. Ecozon@, 1(1), 17-21. . (2011). Ecocriticism's Theoretical Discontents. Mosaic, 44(2), 153-169.

Ostria, M. (2008). Una lectura ecocrítica de textos huidobrianos. Anales de Literatura Chilena, 9, 221-234.

- (2010a). Globalización, ecología y literatura. Aproximación ecocrítica a textos literarios latinoamericanos. Kipus. Revista Andina de Letras, 27, 97-109.

. (2010b). Notas sobre ecocrítica y poesía chilena. Atenea, 502, 181-191.

Oyarzún, L. (1973). Defensa de la Tierra. Santiago: Universitaria.

Pérez, F. (1999). El Diario íntimo de Luis Oyarzún: Una lectura. Revista Chilena de Literatura, 55, 103-128.

Prado, M. (2010). Poesía, espacio/paisaje e identidades en las literaturas latinoamericanas. Cuadernos de Pensamiento Latinoamericano, 17, 109-124.

Richard, N. (2001). Antidisciplina, transdisciplina y redisciplinamientos del poder. En Residuos y metáforas. (Ensayos de crítica cultural sobre el Chile de la transición) (pp. 141-16o). Santiago: Cuarto Propio.

Rodríguez, C. (2005). Weupüfes y machis: Canon, género y escritura en la poesía mapuche actual. Estudios Filológicos, 40, 151-163.

. (2013). Los espacios de la poesía indígena: agenciamientos y metatextos. Taller de Letras, 52, 157-174.

Ruecker, W. (1996). Literature and Ecology: An experiment in Ecocriticism. En C. Glotfelty y H. Fromm (eds.), The ecocriticism reader: Landmarks in literary ecology (pp. 105-123). Athens, Georgia: University of Georgia Press.

Schoennenbeck, S. (2012). Muerte en el paraíso: una visita a la representación del jardín en la obra de María Luisa Bombal (1910-1980). Altre Modernità, 7, 64-78.

Villarroel, R. (1997). Vecindad y copertenencia en el decir poético de Neruda. Cyber Humanitatis, 4. En http://web.uchile.cl/publicaciones/cyber/o4/ textos/rvillarroel.html.

White, S. (2009). Los ríos en la poesía chilena: nuevas definiciones ecocéntricas de la poesía épica y lírica. Agulha, 67. En http://www.revista.agulha. nom.br/ag67white.htm.

Zalasiewicz, J.; Williams, M.; Steffen, W. y Crutzen, P. (2010). The New World of the Anthropocene. Environmental Science \& Technology 44, 2228-2231. Recuperado de http://pubs.acs.org/doi/pdf/10.1021/es903118j

Zapata, J. (2009). Presentación. Acta Literaria, 38, 5-7. 